\title{
2002 Mineralogical Society Schlumberger Medal
}

\author{
Presentation by the President, Prof. B.J. Wood, to Prof. C.J. Hawkesworth, at the Spring \\ Meeting Conference Dinner, Glasgow, 15 April, 2003
}

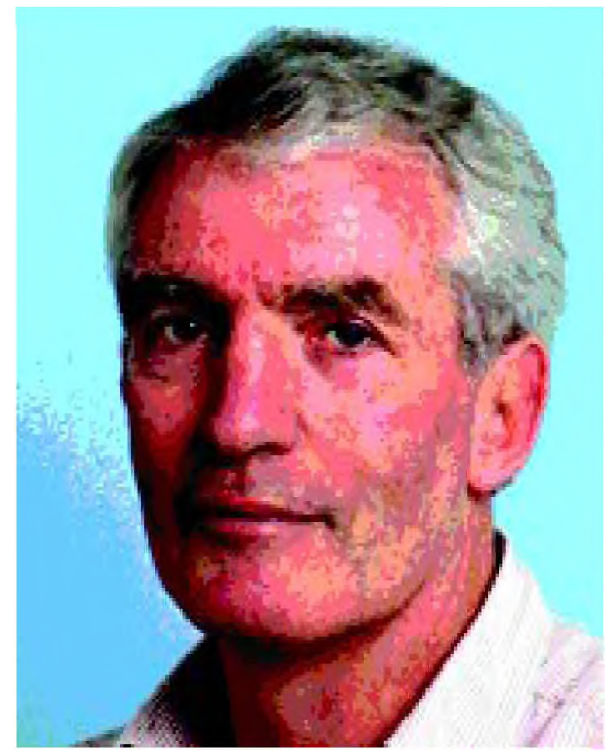

Prof. C.J. Hawkesworth

I am delighted to introduce Professor Christopher Hawkesworth as the 2002 recipient of the Schlumberger Medal. Chris has long been seen as one of the leaders in modern isotope and trace element geochemistry. His contributions range widely in geochemistry, petrology and geology more generally, and include studies of mountain building, subduction-related magmatism, the rates of magmatic processes, the relationships between magmatism and tectonics, mantle processes, and palaeoenvironments and archaeology. Chris is an extremely creative scientist whose formidable impact on our science is represented by well over 200 peer-reviewed publications in top journals and books. His breadth of understanding, combined with a knack for developing novel geochemical tests have repeatedly yielded important insights into complex natural phenomena.

As a research student with Ron Oxburgh, Chris was a member of a group that developed one of the first thermal models for a young mountain belt. He undertook early studies of how heat production varies with depth in the crust, and developed a plate tectonic model for the Austrian Alps that overturned the prevailing view at that time. A similar approach was applied to a deeply eroded $500 \mathrm{Ma}$ mountain belt in Namibia, where he undertook the first in-depth study of the intracrustal changes that occurred within a single orogen and constrained the relative roles of intracrustal melting and sediment reworking, in determining upper crustal compositions. He established the rate of recycling of the upper crust in Britain, undertook one of the first studies of the Nd isotope composition of the lower crust, and determined the crustal growth curves for southern and NE Africa.

Notwithstanding the contributions outlined above, Chris is perhaps best known for his outstanding research on arc processes and enrichment of the mantle. He undertook the first isotope and trace element comparison of islandarc and back-arc volcanic rocks from the same area to isolate the contribution of recycled material from the subducted oceanic crust. With a large number of case studies he then established 
the need for three components to be present in island arc magmas, and challenged models in which average continental crust is considered to be generated above geologically recent subduction zones. He undertook some of the earliest analyses of element fluxes in island arc magmas. This enabled him to develop criteria for identifying the contributions from subducted sediments and from fluids released by dehydration of the basaltic oceanic crust. Such criteria remain central to current debates over models of melt generation above subduction zones.

Using uranium-series disequilibria Chris determined that the fluid and sediment components in island arc rocks are transferred from the subducting slab at significantly different rates and hence by different mechanisms. The hydrous fluids are transferred in as little as 30,000-60,000 years, whereas the sediment component is much more closely linked to the rates of convection in the mantle wedge, and it therefore takes $\sim 2-4$ Ma. For the first time it is now possible to constrain the mechanism of fluid transfer to be linked to hydraulic fracturing, and the thermal structure of the subducted crust to be such that sediments melt at relatively shallow depths $(\sim 50 \mathrm{~km})$. Another application of short-lived isotopes is in determining the pre-eruption history of lavas from active volcanoes, not least to improve on current models for the causes of volcanic eruptions. Chris showed that magma residence times range from negligible in the case of the Auckland volcanic field to 60,000 years for subduction-related andesites, and that there are close links between magma residence times and compositions. He also developed models to evaluate the separate evolution of crystals and melt from short-lived isotope data.

Another area of Chris' interests is in continental flood basalt (CFB) magmatism. He determined the ages and internal stratigraphy of CFB which in turn constrain how the sources and sites of magmatism and eruption rates, have changed with time. Chris overturned models in which all CFB were generated within mantle plumes, by showing that magmatism in some CFB continued for up to $10 \mathrm{Ma}$, and that such CFB were very largely derived from source regions at relatively shallow levels in the sub-continental (lithospheric) mantle. He developed quantitative models for the generation of certain CFB from within the mantle lithosphere, partial melting in response to conductive heating by a mantle plume, and for the evolving magmatic record during continental break-up and separation, taking account of the uplift and cooling history preserved in apatite fission track ages. Subsequently, Chris developed a simple numerical model to constrain the amounts and rates of melt generated under finite duration extension, which predicts testable differences in the volcanic record during continental break-up associated with plume- and lithosphere-derived CFB. Chris has further argued that the break-up of mega-continents such as Gondwana is the predictable response to plate forces on lithosphere that has been weakened by a prolonged plume flux, and that it does not require the emplacement of unusually large plumes. Chris was one of the first to discuss the isotope variations in mantle-derived rocks in terms of intramantle enrichment processes, distinguishing between the effects of small degree melts, hydrous and carbonatitic fluids. The evidence was compiled through a number of case studies on mantle xenoliths, kimberlites and carbonatites. Chris was the first to invert the data on CFB to demonstrate that their source regions in the mantle lithosphere were less dense than those in the convecting upper mantle, and that melting took place in the presence of small amounts of water and other volatiles.

In addition to his direct scientific contributions Chris has had an enormous impact through the mentoring of a large number of students and postdocs and through his work for our scientific community. $\mathrm{He}$ is an excellent citizen, having served as editor of Earth and Planetary Science Letters, as President of the European Association for Geochemistry and most recently as chair of the earth sciences research grants committee for NERC. He is, in all respects an outstanding ambassador for the mineralogical sciences and an extremely deserving recipient of the highest award which the Society can bestow.

\section{Acceptance speech by Prof. Chris Hawkesworth for the Schlumberger medal for 2002}

Bernie, colleagues and friends. Thank you very much for those kind words, and for the Schlumberger Medal for 2002, which I am honoured and delighted to accept.
I feel very fortunate to have been awarded this honour, and particularly perhaps in a field like isotope geology that relies on the development of successful research teams, it reflects the contribu- 
tions of a large number of people. There is an immense debt of gratitude to Ron Oxburgh who took on this Irish student to do a $\mathrm{PhD}$ at a time when I knew relatively little earth sciences, and to the other graduate students working in Oxford on the Eastern Alps who tried hard to remedy that situation, Mike Bickle, David Waters and Philip England. This was a very exciting group to be part of, different people contributed different skills and insights, and the pleasure of working in a good team was reinforced early. Keith O'Nions tempted me across into isotope and trace element geochemistry, and has offered continuous help and encouragement ever since.

The second lucky break was to be offered a position at the Open University in 1979. In those days it was difficult to see how funds might be raised to start a new isotope research group in the $\mathrm{UK}$, and yet Ian Gass was very aware that most good departments worldwide had such a group. He therefore persuaded the Open University to invest in isotope geochemistry, and that contributed to its establishment as an internationally recognized Earth Sciences department. This new research group was set up with Peter van Calsteren and Andy Gledhill, and subsequently Mabs Gilmour, having key roles. Martin Menzies returned from North America to be an early post doc and Gareth Davies was the first $\mathrm{PhD}$ student in isotope geochemistry. Hugely rewarding Australian links were developed through Janet Hergt and Simon Turner, and I greatly enjoyed working closely with Open University colleagues Steve Blake, Nigel Harris, Simon Kelley, Peter Francis and Nick Rogers. Almost $40 \mathrm{PhD}$ students worked in the isotope laboratories, and they all contributed fully to the success of the group. Gareth Davies, Tim Elliott, Linda Kirstein, Peter Lightfoot, Frank McDermott, Dave Peate and Marcel Regelous are among those active in research and perhaps known to members of the Society. All these people, and many more, have contributed to the research cited in this award, and it is a great pleasure to acknowledge my gratitude here.

The Open University was a wonderful place to be, it was young and optimistic, it had reasonable funding, and it encouraged areas of strong research and scholarship. Nonetheless, the challenge of setting up a new research group at Bristol has been richly rewarding. Tim Elliott, with Simon Turner and Chris Coath, has been responsible for the new laboratories, and many post docs and graduate students have already made a significant impact. Colleagues have been warmly welcoming, despite the inevitable upheavals associated with the development of a new isotope group, and exciting new research projects are underway.

In many ways it feels strange to stand here to accept a medal in mineralogy, but it highlights the huge changes that have been gradually taking place within societies such as this. When I was a student, mineralogy had a dry and fusty air about it; crystallographic axes and dusty models of mineral structures seemed a long way from the excitement of plate tectonics and holistic models of earth evolution. But increasingly, and arguably in one of the better kept secrets, mineralogical societies have embraced new topics and subject areas with great enthusiasm. This Spring Meeting of the Mineralogical Society in Glasgow is on the Evolution of the Earth's Surface, and the lectures range from a review of weathering projects to the origin of the earth, from magmatic time scales to the use of U-He and Be isotopes to determine the ages of glacial deposits and weathering rates in different tectonic settings. This Society is increasingly regarded as a cornerstone of academic research, and the challenge is to ensure that is more widely understood, almost despite the society's name. How does it become more widely appreciated that the term Mineralogy stands for new and exciting advances across broad areas in the Earth Sciences, when increasingly that is the Society's role and ambition?

It is a delight to be back in Glasgow, and especially so in this period of exceptional warm spring weather. Here too many secrets are hidden, and much is the delight in their rediscovery. But as universities in England struggle with issues of research funding, whether there should be teaching-only universities, and how small should be the elite group that concentrates on world class research, it highlights how different the issues are under the flags of devolution in Scotland and in Wales, or in Ireland. Concentrating resources into a small number of universities builds on the notion that the number of high-quality research scientists in any country is limited, and that a sensible use of central funds is to ensure that they are well supported in the best possible academic environments. Quality feeds off quality, and so it is argued that those academic environments will be small in number, as in just a small number of universities. But such a pyramid approach implies larger numbers of less research-active universities to underpin the best, and as a broad-based scouting ground for future talent. Leaving aside 
for the moment the general merits and limitations of such a structure, it is clearly extremely difficult to implement in countries with a small number of universities. Can there be a viable pyramid with just one university on the top? Can quality be ensured without meaningful competition? It is difficult to see how such questions can be answered in the affirmative, and so the funding guidelines may need to very different in smaller countries. Perhaps we should downgrade the emphasis on high quality universities, and aim instead at first-rate departments in different universities in different subject areas. The advantage of a smaller community should be better communication, and hence less need to develop a system in which most of the good departments are on one university campus.
I have taken more than enough of your time. I feel very fortunate to be in isotope geochemistry with its great potential to contribute in many areas of the Earth and other sciences. It has a supportive community with sufficient competitive edge to ensure the best science without being destructive, and that should certainly be our aim. None of this would have been possible without the help and support of my wife Celia, and I'm delighted that she is here this evening. In times when university life can feel under increasing pressures, it is a pleasure to record that we have greatly enjoyed the freedom, challenges and changing interests of shared university careers. Thank you very much for the Mineralogical Society-Schlumberger Medal 2002. 